УДК 550.3

ПРИМЕНЕНИЕ ГЕОФИЗИЧЕСКИХ МЕТОДОВ ДЛЯ ВЫЯВЛЕНИЯ

НЕБЛАГОПРИЯТНЫХ ИНЖЕНЕРНО-ГЕОЛОГИЧЕСКИХ УСЛОВИЙ НА ОБЬЕКТЕ ГОРНО-ОБОГАТИТЕЛЬНЫЙ КОМБИНАТ НА ЗОЛОТО-СУРЬМЯНОМ МЕСТОРОЖДЕНИИ «СЕНТАЧАН»

\author{
Гриб Н.Н., Сясько А.А., Качаев А.В., Кузнецов П.Ю. \\ ФГАОУ ВПО «Технический институт (ф) СВФУ им. М.К. Аммосова», \\ Нерюнгри,e-mail: grib@nfygu.ru
}

\begin{abstract}
Для выявления неблагоприятных инженерно-геологических условий проектируемого горного предприятия использовались геофизические методы. Геофизические исследования, включающие в себя методы сейсморазведки и электротомографии, позволили обеспечить возможность получения детальной и надежной информации об особенностях инженерно-геологического строения участка исследования. На первом этапе интерпретации геофизических данных результаты работ были представлены в виде скоростных разрезов и разрезов логарифмов электрических сопротивлений. Следующий этап анализа геофизических данных - определение положения вероятных интервалов распространения льдов и существенно льдистых пород в плане. Для интегрированной оценки льдистости разреза оценивалось среднее сопротивление тридцатиметровой толщи пород. Построенный интегрированный план изолиний для тридцати метровой толщи позволяет оценить возможное положение интервалов распространения льдов и льдистых пород в плане. Точнее определить степень опасности того или иного интервала позволил анализ данных сейсморазведки КМПВ, области аномально высоких электрическим сопротивлений совпадают с интервалами наиболее низких скоростей распространения упругих волн. Подобным набором физических характеристик обладают рыхлые или сильно трещиноватые скальные, с высоким процентом льдистости, породы и, конечно же, погребённые льды.
\end{abstract}

Ключевые слова: геофизические методы, электротомография, сейсморазведка, инженерно-геологические условия, льдистые породы, погребённые льды

\title{
THE USE OF GEOPHISICAL METHODS FOR DETERMINING NEGATIVE ENGINEERING-GEOLOGICAL CONDITIONS AT THE MINING PLANT OF «SENCHAN» GOLD-STIBIUM DEPOSIT
}

\author{
Grib N.N., Syasko A.A., Kachaev A.V., Kuznetsov P.Yu. \\ Technical Institute (branch) of «North-Eastern federal university at M.K. Ammosov», \\ Neryungri,e-mail: grib@nfygu.ru
}

\begin{abstract}
Geophysical methods were used to determine the negative engineering-geological conditions of a mining enterprise. Those methods including seismic exploration and electrical tomography enabled us to get all necessary detailed and reliable information about the features of engineering-geological construction site at the area. At first stage of geophysical evidence interpretation the work products were represented as vilocity profiles and logarithm stacks of electrical resistances. Next stage of geophysical evidence analysis was to determine the positions of possible space intervals of ice spreadings and mainly icy rocks in the ground range. The average resistance of 30 meter rock mass was estimated to integrate valuing of the ice content stack. The isoline integrated plan for the 30 meter rock mass allowed us to estimate possible positions of an ice interval spreading and icy rocks appreciably in the ground range. Refraction correlation method of refracted waves data analysis allowed to determine the risk degree more exactly. The areas of irregular high electrical resistance concur with the lower speeds of elastic waves spreading intervals. Loose or vastly fractured rocks with a high rate of ice content and connate ice possess elastic wave spreading.
\end{abstract}

Keywords: geophysical methods, electrical tomography, seismic exploration, geological conditions, icy rocks, connate ice

На современном этапе развития горной промышленности Якутии отмечается развитие новых горных предприятий и интенсификация вовлечения в отработку ранее разведанных месторождений полезных ископаемых. При этом стоит отметить, что освоение любых месторождений полезных ископаемых представляет собой четкую систему, представленную поочередно сменяющимися этапами освоения геологического пространства, занятого полезным ископаемым, а также территорей непосредственно прилегающей к области распространения залежи полезного ископаемого. Одним из ключевых этапов этой системы является инженерно-геологическое обоснование площади проектируемого строительства горного предприятия. Корректная постановка и выполнение изыскательских работ на данном этапе является необходимым условием для реализации процесса включения и бесперебойного участия проектируемого горного предприятия в инфраструктуре отрасли, а также успешного взаимодействия его со смежными отраслями производства. 
В геологическом строении объекта исследований принимают участие отложения верхнего триаса норийского яруса $\left(T_{3} n_{2}\right)$, перекрытые с поверхности чехлом верхнечетвертичных и современных отложений озерно-болотного (lb $\left.\mathrm{Q}_{\text {III-IV }}\right)$, элювиальноделювиального (ed $\mathrm{Q}_{\text {III-IV }}$ ) генезисов и современными отложениями пролювиальноделювиального генезиса (pd Q $\mathrm{IV}$ ) [3].

Отложения верхнего триаса норийского яруса $\left(T_{2} n_{2}\right)$ имеют повсеместное распространение в пределах всей площади исследований, вскрыты под четвертичными отложениями с глубины 0,9-4,4 м вскрытой мощностью 2,4-8,2 м.

Отложения представлены алевролитами очень низкой прочности, залегающими в кровле скального массива, сильновыветрелыми до дресвы, щебня, супеси и суглинка, мощностью 0,4-4,4 м, ниже - алевролитами малопрочными средней прочности и прочными серого и темно-серого цвета, сильнотрещиноватыми, трещины ориентированы в основном хаотично, реже - под углами 0-5 и 40-45 к оси керна, выполнены мерзлым супесчаным материалом и льдом.

Мерзлотные условия района работ характеризуются сплошным распространением вечномёрзлых грунтов, мощностью более 300 м. По динамике температурного режима в годовом цикле выделяются: слой сезонного оттаивания и толща вечномёрзлых грунтов [3].

На период изысканий грунты слоя сезонного оттаивания до глубины 0,3-1,2 м находились в талом состоянии, ниже - в твёрдомёрзлом состоянии массивной, слоистой и корковой криогенной текстуры, при оттаивании грунты от средней степени водонасыщения до водонасыщенных, - суглинок при оттаивании от мягкопластичного до текучего.

Температура грунтов на глубине годовых нулевых амплитуд изменяется от минус 6,0 до минус $7,8^{\circ} \mathrm{C}$. Нормативная глубина сезонного оттаивания составляет 1,6 м на заболоченных участках и 2,5 м на сухих участках.

Целью выполненных исследований на объекте горно-обогатительный комбинат, золото-сурьмяном месторождении «Сентачан», являлось выявление и оценка пространственного распространения неблагоприятных инженерно-геологических условий в зоне расположения технических и производственных сооружений для дальнейшей разработки мероприятий, обеспечивающих безаварийную эксплуатацию вышеупомянутой системы. Для решения поставленной задачи был использован комплекс геофизических методов $[1,5]$.

Инженерно-геофизические исследования позволили уточнить геологическое строение площади и выделить потенциально опасные для функционирования проектируемых сооружений инженерно-геологические проявления, одно из направлений, это выделение интервалов существенно льдистых пород и погребенных льдов.

Геофизические исследования, включающие в себя методы сейсморазведки и электротомографии, позволили обеспечить возможность получения детальной и надежной информации об особенностях инженерно-геологического строения участка исследования.

Во-первых, отметим высокую детальность выполненных изысканий - шаг сейсмоприёмников по профилям 2 м, шаг электродов электротомографии - 5 м. В обоих случаях применено непрерывное профилирование, при электротомографии - с 50\% перекрытием.

На первом этапе интерпретации геофизических данных результаты работ были представлены в виде скоростных разрезов и разрезов логарифмов электрических сопротивлений (рис. 1).

Наиболее информативными оказались длинные профили субширотного простирания № 0-3. Прежде всего, на разрезах удельных сопротивлений выделяются приповерхностные интервалы пород с весьма высокими показателями сопротивлений, мощность выделенных зон - до 10-12 м, зоны повторяются на всех четырёх профилях, протяженность зон от пикета 150 м до конца профиля (рис. 1). Сопоставление выделенных зон с данными бурения позволило подтвердить происхождение рассматриваемых аномалий с наличием в изучаемом разрезе разуплотнённых льдистых пород. Области пород весьма высокого сопротивления совпали в разрезе с интервалами развития погребенных льдов, выделенными по данным бурения. Более того, даже морфология аномалий повышенных сопротивлений совпадает с границами инженерно-геологических разрезов.

Идентификация рассматриваемых аномалий высоких сопротивлений как аномалий, обусловленных наличием в разрезе льдов и существенно льдистых пород, обусловила следующий этап анализа геофизических данных - определение положения вероятных интервалов распространения льдов и существенно льдистых пород в плане [4]. 
Для этого данные электротомографии по отдельным профилям были сведены в единый массив с пространственной привязкой $X, Y, Z$ каждой точки измерения. К сожалению, визуализация всего массива трёхмерных данных существенно осложнена сложным геоэлектрическим строением разреза. Как альтернатива был выбран метод погоризонтных срезов [2]. Для построения среза, например, плана сопротивлений пород на интервале глубин 3-5 метров (рис. 2) из полного массива данных выбирались точки, расположенные в этом интервале глубин. По данным вновь полученного массива строился план изолиний, при этом данные по точкам, координаты $X$ и $Y$ (положение в плане) которых совпадают, сопротивления усреднялись. Таким образом, полученный в результате план изолиний логарифмов удельных сопротивлений на интервале глубин 3-5 м отображает удельное электрическое сопротивление слоя породы мощностью 2 метра с глубиной положения почвы слоя 5 м.

На рис. 2 приведены построенные по этому принципу погоризонтные планы изолиний логарифмов удельных сопротивлений для интервалов глубин $3-5,5-8$ и 8-10 метров. Крупные синие точки на рисунках обозначают плановое положение инженерно-геологических скважин, при бурении которых были вскрыты льды.

Приведённые на рис. 2 планы наглядно иллюстрируют конфигурацию вероятных областей распространения подземных льдов и существенно льдистых пород. Анализ погоризонтных планов позволил оценить и глубинность распространения льдов и существенно льдистых пород - значимые аномалии высоких сопротивлений распространены до глубин порядка 10 м от дневной поверхности.

Для интегрированной оценки льдистости разреза была произведена обработка исходного массива, содержащего данные об электрических сопротивлениях горных пород на глубинах от 0 до 30 м. При пересчёте сопротивление координатной точке в плане оценивалось как среднее значение сопротивлений в этой точке по всему интервалу глубин, т.е. оценивалось среднее сопротивление тридцатиметровой тощи пород. Результат построений приведен на рис. 3, а. Цветовая шкала логарифмов удельных сопротивлений ко всем построенным планам изолиний приведена на рис. 2.
Построенный интегрированный план изолиний для тридцатиметровой толщи (рис. 3, а) позволяет оценить возможное положение интервалов распространения льдов и льдистых пород в плане. Наиболее опасные места выделены голубым цветом, соответствующим средним электрическим сопротивлениям от 10000 Ом'м и выше. Также потенциально опасными представляются интервалы распространения пород с сопротивлениями более 3162 Ом'м (изолиния логарифма удельного сопротивления 3,5 на рис. 3 , а).

Выделенные интервалы на данном этапе анализа представляются как потенциально опасные. Точнее определить степень опасности того или иного интервала позволит анализ данных сейсморазведки КМПВ.

По аналогии с анализом данных электротомографии, для визуализации результатов сейсморазведочных исследований выбран метод погоризонтных срезов. На рис. 4 приведены погоризонтные планы изолиний скоростей упругих волн для интервалов глубин 3-5, 5-8 и 8-10 метров.

При анализе результатов построений сейсморазведочных данных максимальное внимание уделено ранее выделенным по данным электротомографии областям вероятного распространения льдистых пород и погребенных льдов. Показательно, что эти области на погоризонтных планах скоростей распространения упругих волн совпадают с интервалами наиболее низких скоростей. Построение плана скоростей, рассчитанное по усредненным показателям для толщи мощностью 30 м (аналогично построениям на рис. 3, a), подтвердило вывод о весьма хорошем совпадении в плане аномалий высоких удельных сопротивлений с аномалиями низких скоростей (рис. 3, б).

Учитывая, что скорость распространения упругих волн пропорциональна плотности пород, по итогам описанных выше построений имеем следующее: предварительно выделенные по данным электроразведки интервалы пород с аномально высокими электрическими сопротивлениями характеризуются также пониженными значениями плотность горных пород на этих интервалах.

Подобным набором физических характеристик обладают рыхлые или сильно трещиноватые скальные, с высоким процентом льдистости, породы и, конечно же, погребённые льды. 

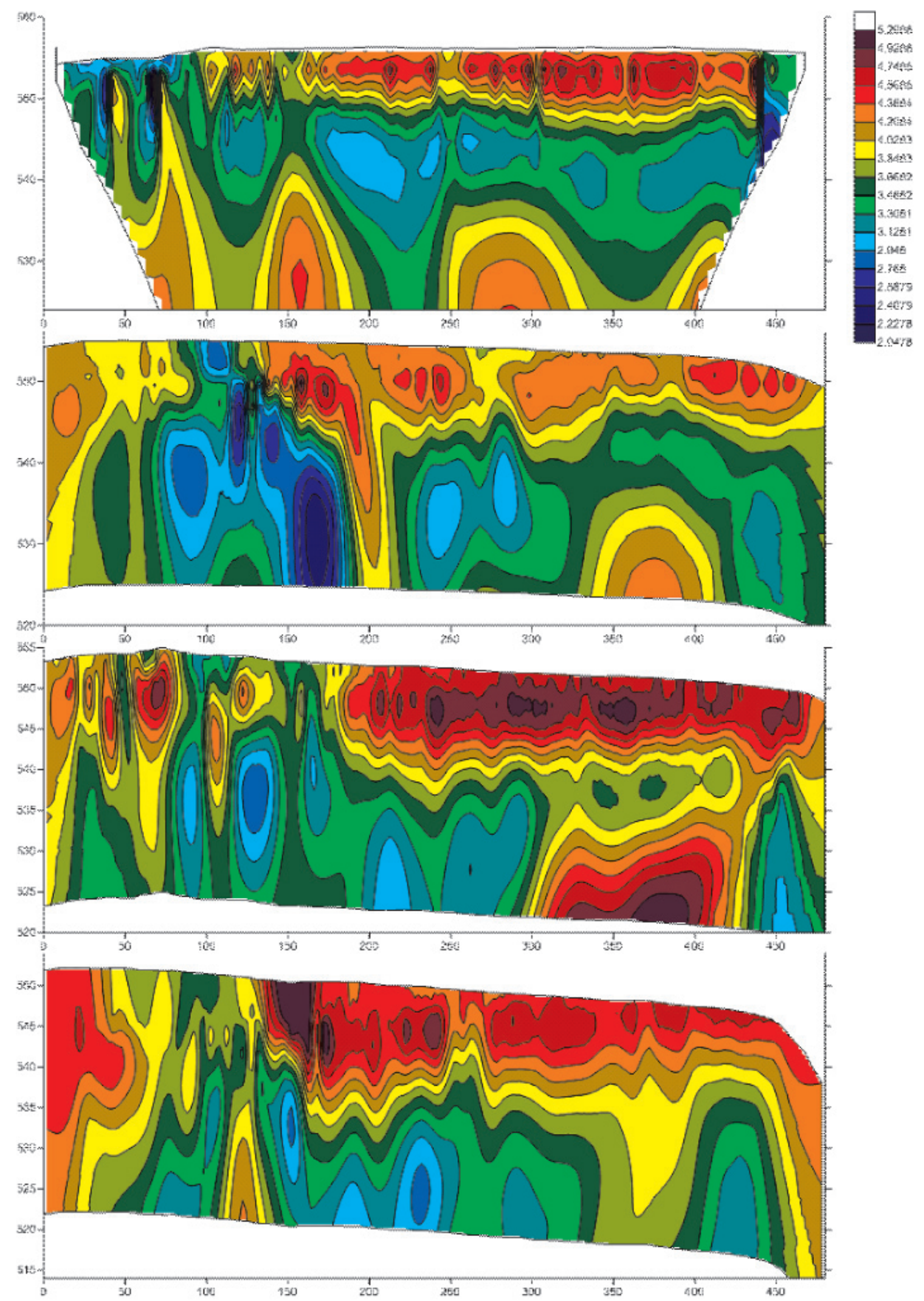

Рис. 1. Разрезы логарифмов удельных сопротивлений по профилям 0-3 


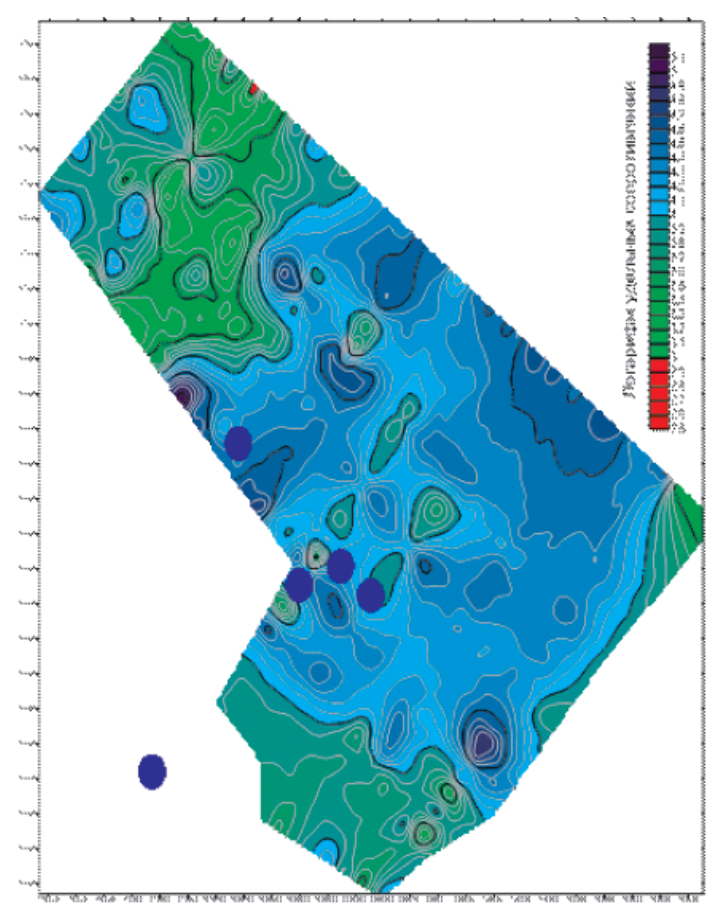

a

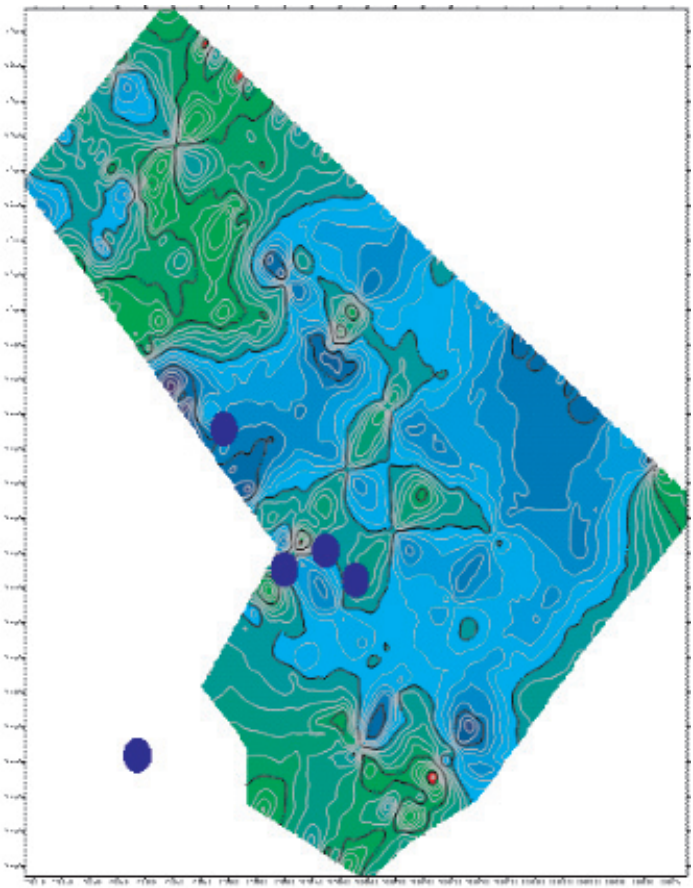

6

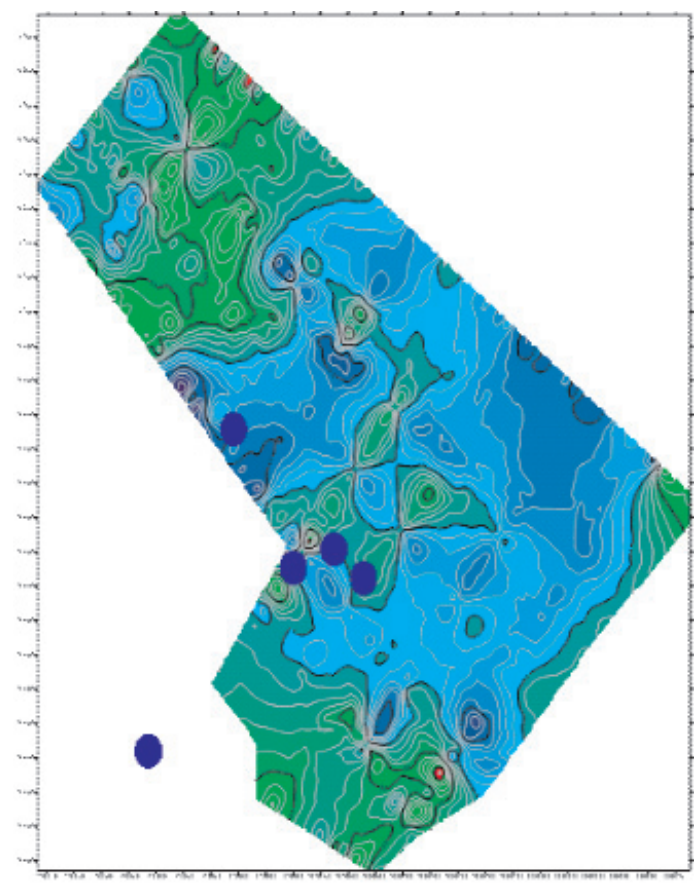

B

Рис. 2. План логарифмов удельных сопротивлений на глубине:

$$
a-3-5 \mu ; \sigma-5-8 . м ; в-8-10 \text { м. }
$$

Для более точного выделения интервалов с минимальными скоростными показателями и максимальными сопротивлениями было произведено нормирование плана скоростей распространения упругих волн на план логарифмов удельных сопротивлений. В результате получен план изолиний, физический смысл которого состоит в следующем - минимальные значения изолиний соответствуют интервалам с очень низкими скоростями распространения упругих волн и высокими значениями удельного сопротивления пород, или, что очень вероятно интервалам с наличием погребенного льда или сильно льдистых пород в разрезе. Для нормировки использованы усредненные характеристики тридцатиметровой толщи (рис. 4, a, б). 


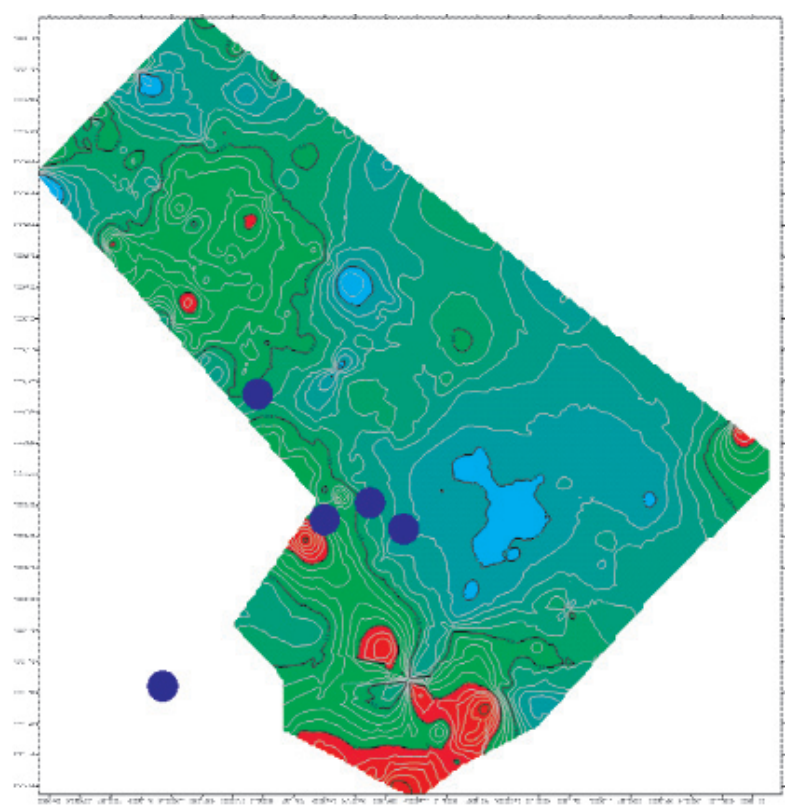

a

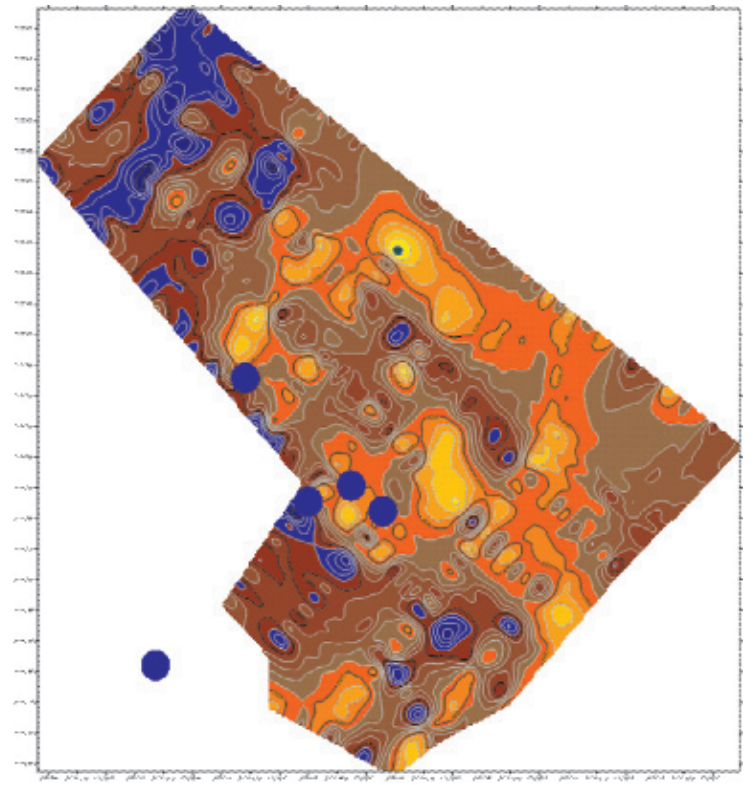

6

Рис. 3. Усредненные показатели геофизических параметров для тридияатиметровой толщи:

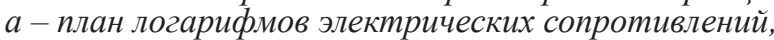

б - план скоростей распространения упругих волн

Результат построений представлен на рис. 5. Скважины, вскрывшие погребенные льды, на этом рисунке обозначены красными точками. При анализе результатов следует, что потенциально опасными с точки зрения высокой вероятности наличия льдов и существенно льдистых пород в разрезе следует считать области, попадающие в интервал нормированного показателя менее восьми (от изолинии 8 и менее).

Таким образом, в результате выполнения геофизических исследований тех- нологической площадки проектируемого горного предприятия были выявлены чрезвычайно опасные явления - определяющее влияние температурного режима грунтов основания сооружения на безопасность функционирования.

Электротомографические и сейсмологические исследования позволили выделить интервалы и глубину распространения погребенных льдов и сильно льдистых пород, а также их площадное распространение. 


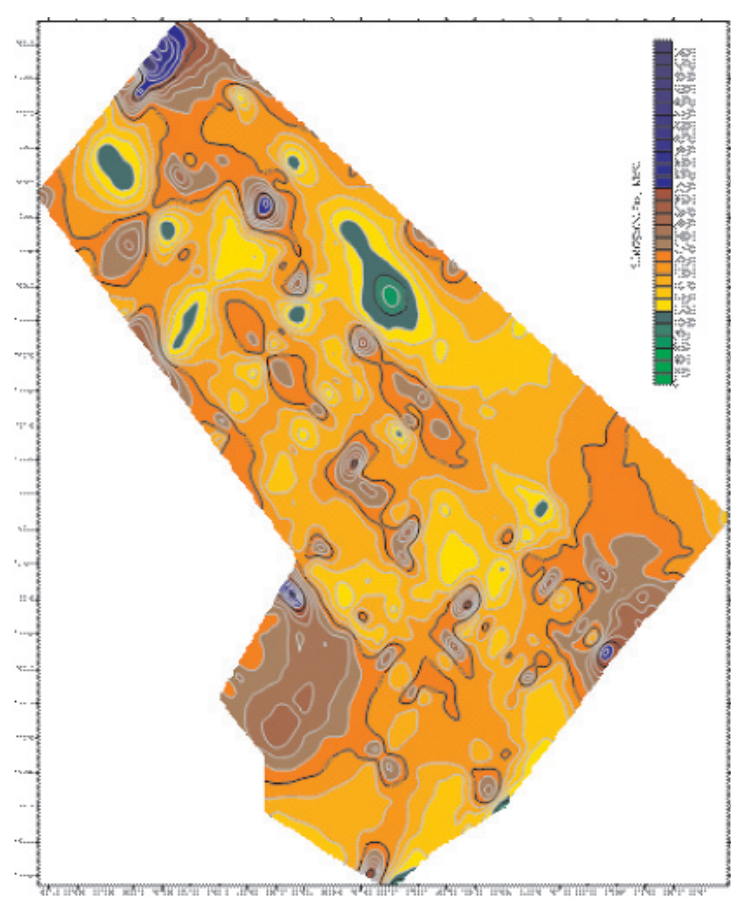

a

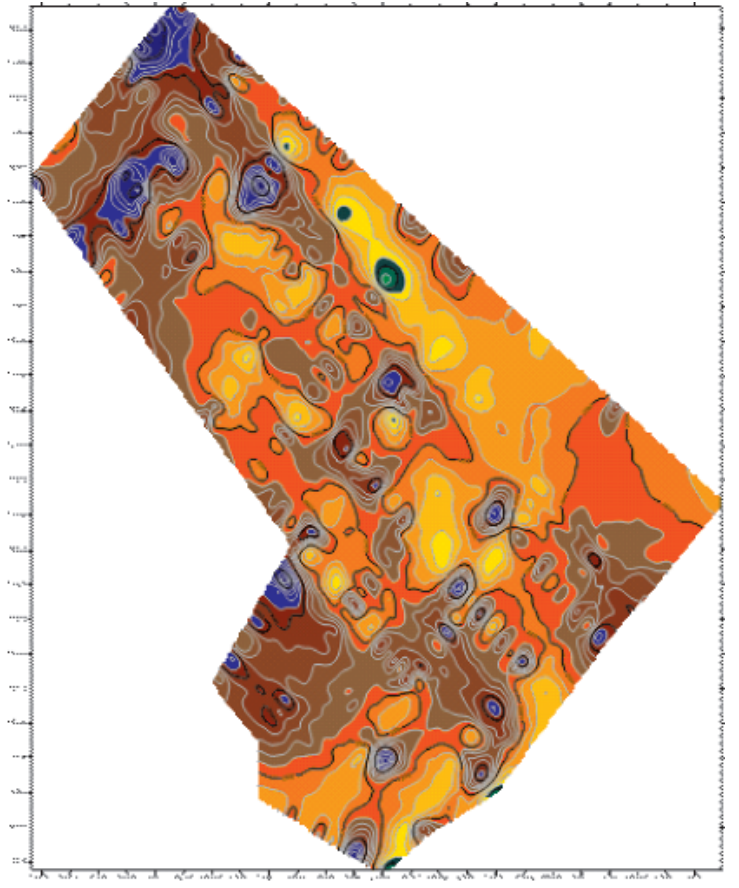

6

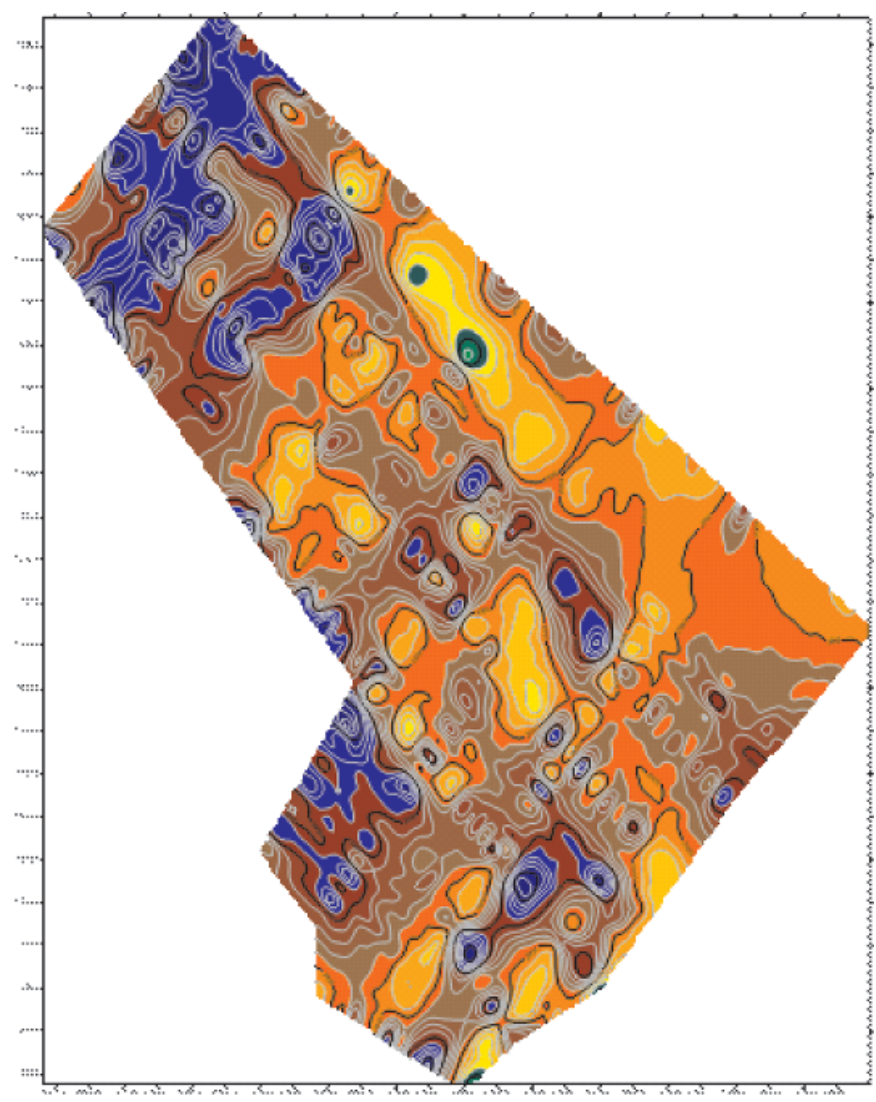

B

Рис. 4. План скоростей распространения упругих волн, интервал глубин: $a-3-5 \mu ; \sigma-5-8 \mu ; в-8-10 \mathrm{M}$ 


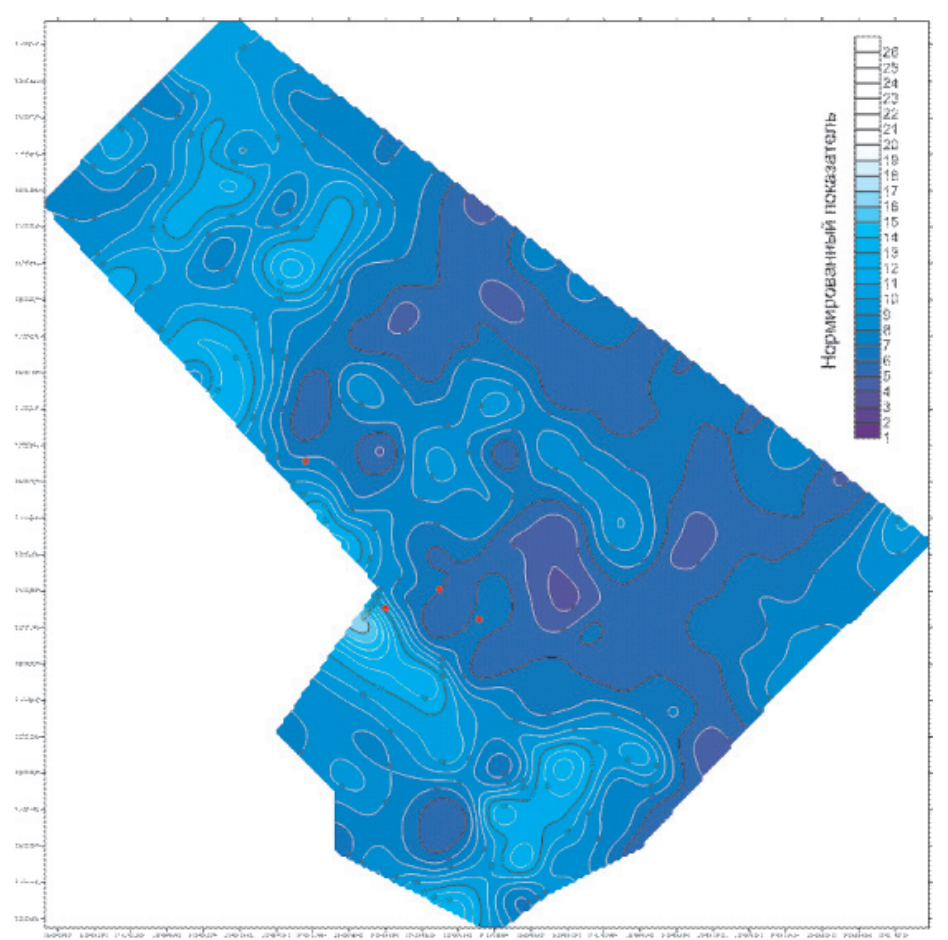

Puc. 5. План изолиний нормированного показателя V/R для тридиатиметровой толщи

\section{Список литературы}

1. Воронков О.К. Инженерная сейсмика в криолитозоне (изучение строения и свойств мерзлых и талых горных пород и массивов). - СПб.: Изд-во ОАО «ВНИИГ им. Б.Е. Веденеева», 2009. - 401 с.

2. Кобрунов А.И. Математические основы теории интерпретации геофизических данных: учеб. пособие. - М.: ЦентрЛит-НефтеГаз, 2009. - 288 с.

3. Отчет об инженерно-геологических изысканиях по объекту: «Горно-обогатительный комбинат на золото-сурь- мяном месторождении «Сентачан», фонды ООО «Нерюнгристройизыскания». - Нерюнгри, 2015. - 100 с.

4. Павлова А.М., Шевин В.А. 3D-Электротомография при исследовании ледниковых отложений // Геофизика. 2013. - № 6. - С. 32-37.

5. СП 11-105-97. Инженерно-геологические изыскания для строительства. Часть VI. Правила производства геофизических исследований. [Электронный ресурс]. - Режим доступа: http://www.internet-law.ru/stroyka/text/45007/ (дата обращения (1.03.16). 